\title{
The renin angiotensin system in the development of cardiovascular disease: role of aliskiren in risk reduction
}

\author{
Paolo Verdecchia' \\ Fabio Angeli' \\ Giovanni Mazzotta' \\ Giorgio Gentile 2 \\ Gianpaolo Reboldi² \\ 'Department of Cardiology, Clinical \\ Research Unit 'Preventive Cardiology', \\ Hospital 'Santa Maria della \\ Misericordia', and Fondazione Umbra \\ Cuore e Ipertensione - AUCI Onlus, \\ Perugia, Italy; ${ }^{2}$ Department of Internal \\ Medicine University of Perugia, Italy
}

\begin{abstract}
An association has been shown between plasma renin activity (PRA) and the risk of cardiovascular disease. There is also evidence that angiotensin II exerts detrimental effects on progression and instabilization of atherosclerotic plaque. The renin-angiotensin system (RAS) can be inhibited through inhibition of angiotensin I (Ang I) generation from angiotensinogen by direct renin inhibitors, inhibition of angiotensin II (Ang II) generation from angiotensin I by angiotensin-converting enzyme inhibitors and finally by direct inhibition of the action of Ang II receptor level. Aliskiren, the first direct renin inhibitor to reach the market, is a lowmolecular-weight, orally active, hydrophilic nonpeptide. Aliskiren blocks Ang I generation, while plasma renin concentration increases because the drugs blocks the negative feed-back exerted by Ang II on renin synthesis. Because of its long pharmacological half-life, aliskiren is suitable for once-daily administration. Its through-to-peak ratio approximates $98 \%$ for the $300 \mathrm{mg} /$ day dose. Because of its mechanism of action, aliskiren might offer the additional opportunity to inhibit progression of atherosclerosis at tissue level. Hypertension is an approved indication for this drug, which is also promising for the treatment of heart failure. The efficacy of this drug in reducing major clinical events is being tested in large ongoing clinical trials.

Keywords: plasma renin activity, renin angiotensin system, aliskiren, angiotensinogen, renin, hypertension, heart failure, diabetes
\end{abstract}

A link between plasma renin activity (PRA) and risk of cardiovascular disease has been demonstrated in several (Brunner et al 1972; Alderman et al 1991, 1997; Campbell et al 2005), but not all (Doyle et al 1973; Meade et al 1993) epidemiological studies. Such a link is also supported by many experimental and clinical studies which provided convincing evidence that the renin-angiotensin system (RAS) is capable of stimulating atherosclerosis by triggering basic reactions which ultimately lead to growth, instability, and rupture of atherosclerotic plaques and facilitation of thrombosis (Schmidt-Ott et al 2000; Jacoby and Rader 2003) (Figure 1).

\section{Mechanisms of pharmacological inhibition of the RAS}

Correspondence: Paolo Verdecchia Department of Cardiology, Clinical Research Unit 'Preventive Cardiology', Hospital 'Santa Maria della Misericordia' and Fondazione Umbra Cuore e Ipertensione - AUCl Onlus, Strada Tuderte, 6 - 06100 - Perugia, Italy Email:verdec@tin.it
The pharmacological inhibition of the RAS can be achieved through 3 different basic mechanisms (Skeggs et al 1957) (Figure 2):

1) Inhibition of angiotensin I (Ang I) generation from angiotensinogen. This can be achieved by direct inhibition of renin, an aspartyl protease that releases the decapeptide Ang I from the $\alpha$-2-globulin angiotensinogen. 


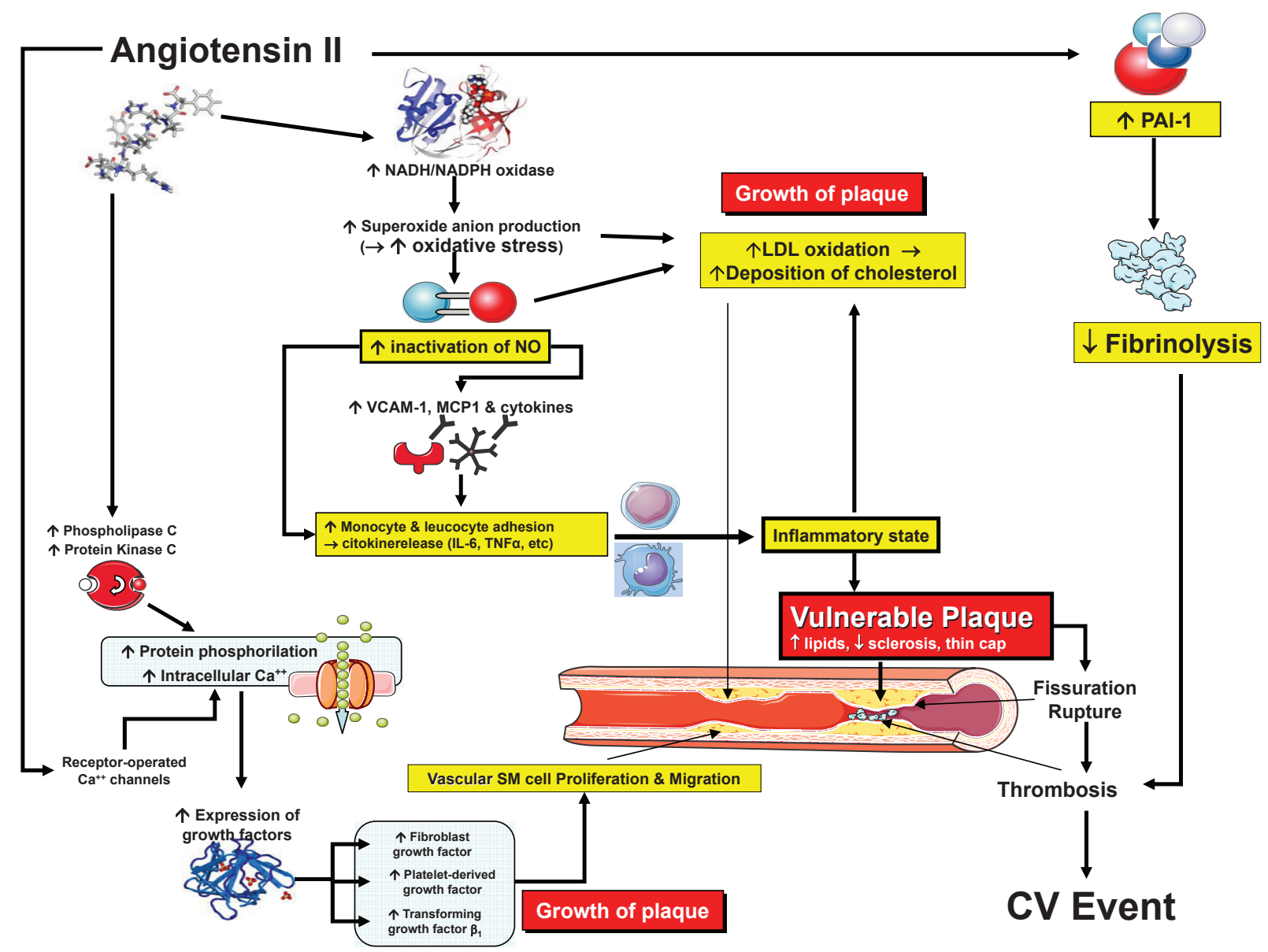

Figure I Mechanisms of the detrimental effects of angiotensin II on atherosclerosis.

2) Inhibition of angiotensin II (Ang II) generation from angiotensin I. This can be achieved through inhibition of angiotensin-converting enzyme (ACE), a zincdependent protease that generates the octapeptide hormone angiotensin II (Ang II) by cleaving 2 amino acids (histidine and leucine) from Ang I. ACE is highly expressed in the kidney and pulmonary endothelium.

3) Inhibition of the action of Ang II at the level of its receptor(s).

In a landmark paper published more than 50 years ago, Skeggs et at (1957), first suggested that inhibition of Ang I generation from angiotensinogen was the therapeutic approach "most likely to succeed" because renin is the initial and rate-limiting step of the RAS.

Unfortunately, at variance with ACE inhibitors and Ang II receptor blockers, direct inhibitors of renin had to wait many years before becoming available for clinical use. Important technical problems in identifying and developing suitable agents sharing an elevated affinity for the renin's active site and sufficient bioavailability to allow oral administration precluded their clinical use for a long time.

\section{Angiotensinogen, prorenin, and renin}

\section{Angiotensinogen: the first substrate}

Human angiotensinogen, the substrate on which renin exerts its activity, is a 118-amino-acid-long polypeptide (an $\alpha$-2-globulin) that is generated mainly in the liver. Other species have angiotensinogen of different sizes. Plasma angiotensinogen levels are increased by Ang II, plasma corticosteroid, estrogen, and thyroid hormones.

How does Ang I origin from angiotensinogen? A 7-amino acid residue of angiotensinogen is accommodated into a deep cleft of renin. This causes hydrolysis of the Leu10-Val11 bond and generation of the decapeptide fragment Ang I (James and Sielecki 1985). Ang I gives origin to the octapeptide hormone Ang II through the action of ACE, a zinc-dependent protease present in several tissues, which 


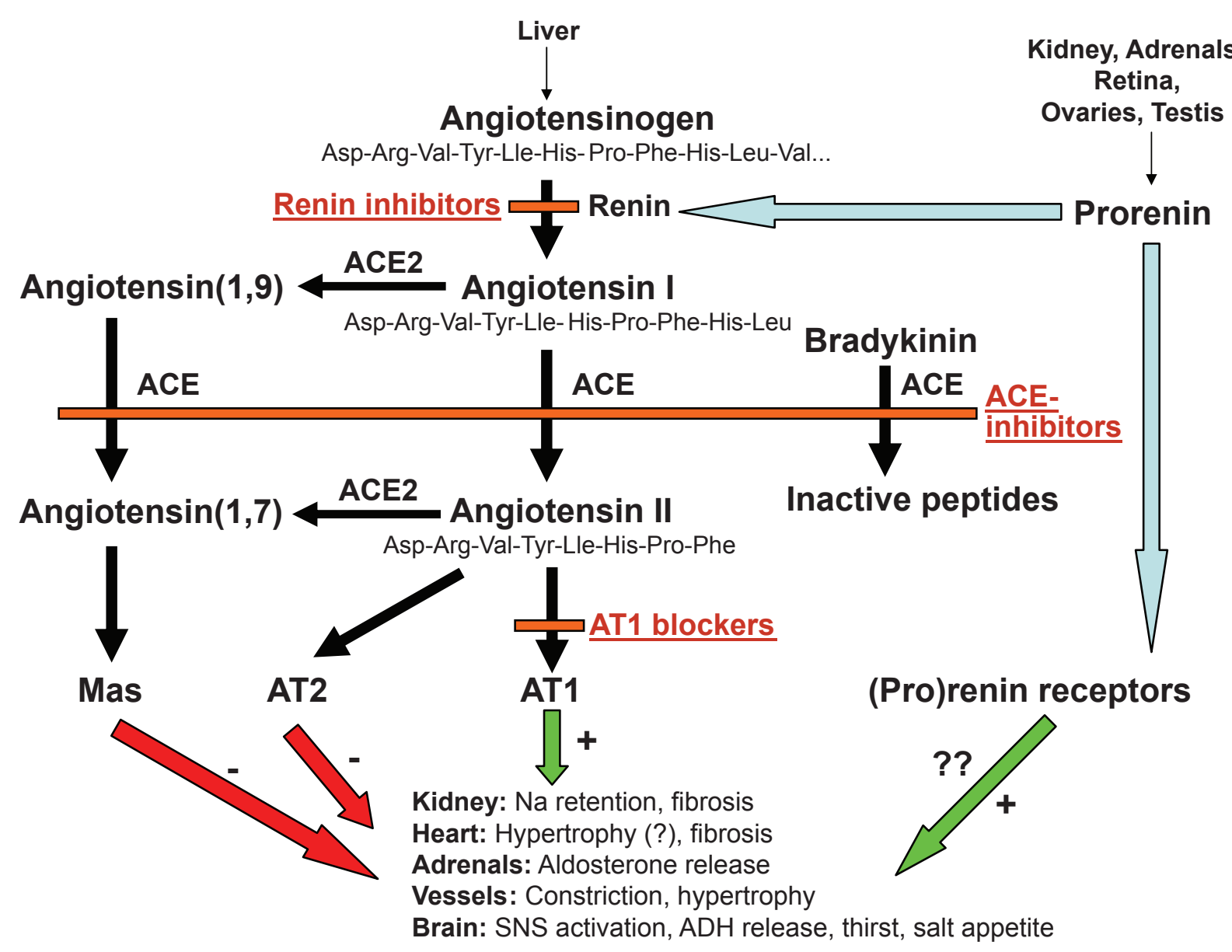

Figure 2 Different levels of pharmacological blockade of the renin-angiotensin system.

cleaves 2 amino acids from Ang I, thus releasing Ang II. Ang I can also be transformed into $\operatorname{Ang}(1,9)$ by ACE2, a carboxypeptidase that also mediates the transformation of Ang II into Ang(1,7) (Donoghue et al 2000). ACE2 has a greater affinity for Ang II than it has for Ang I. The effect of ACE2 on Ang II tends to counterbalance the adverse effects of Ang II.

Ang II binds to 2 main receptors, Ang II type 1 (AT $\left.{ }_{1}\right)$ and Ang II type II $\left(\mathrm{AT}_{2}\right)$. Ang II can also be hydrolyzed by specific proteases to generate other peptides including Ang (1-7), which binds to $\mathrm{AT}_{3}$ receptors, and Ang IV, which binds to $\mathrm{AT}_{4}$ receptors (Turner 2003).

\section{Structure and activity of renin}

Renin, a 340-amino acid protease polypeptide, is a member of the aspartyl protease superfamily, which includes pepsin, cathepsin D, and chymosin (Wood et al 1987). Renin results from a molecular change of its precursor, prorenin. Structurally, renin consists of 2 lobes with a long and deep cleft between them (Sielecki et al 1989; Rahuel et al 2000).

The cleft, the active site of renin, accommodates a 7-amino acid residue of angiotensinogen. Two aspartic acid residues (Asp32 and Asp215 in human renin), each located in a single lobe of renin, control the first and ratelimiting step of the RAS by catalyzing the hydrolysis of the Leu10-Val11 peptide bond of angiotensinogen and releasing the decapeptide Ang I (James and Sielecki 1985) (Fig. 3).

An important point to note is that, at variance with other aspartic proteases such as pepsin or cathepsin D, renin is fully specific for angiotensinogen.

\section{Structure and activity of prorenin}

Prorenin, the inactive precursor of renin, is a pre-hormone synthesized in adrenals, retina, ovaries, and testis (Danser et al 1989; Sealey et al 1988; Itskovitz et al 1992; Clausmeyer et al 1999). The extra renal sites of synthesis explain why nephrectomized subjects show circulating prorenin levels of about $50 \%$ of those in normal subjects. Synthesis in ovaries 
explains why prorenin levels are high in pregnancy (Derkx et al 1987; Itskovitz et al 1987).

Interestingly, Ang I and Ang II in nephrectomized subjects are extremely low despite prorenin levels about half the normal (Derkx and Schalekamp 1988). This finding is consistent with a very low intrinsic enzymatic activity of prorenin ( $<3 \%$ of fully activated renin). In diabetic subjects with prolipherative retinopathy, levels of prorenin in the vitreous are about 100-times higher than in plasma (Wilkinson-Berka 2004).

Administration of prorenin does not cause any rise in blood pressure in experimental animals. It is believed that the absence of enzymatic activity of prorenin is due to a 43-amino acid N-terminal propeptide which covers the enzymatic cleft, thereby denying the access of angiotensinogen to the active site of renin (Figure 3).

Transformation of inactive prorenin into the active form renin is a fundamental reaction that may be irreversible (proteolytic) or reversible (nonproteolytic). The irreversible proteolytic activation occurs in the juxtaglomerular cells of kidney (Reudelhuber et al 1994). It consists of the removal of the 43-amino acid propeptide. It seems to be operated by various enzymes including proconvertase 1 , cathepsin B, trypsin, plasmin, and kallikrein.

The reversible nonproteolytic activation of prorenin consists of a sort of unfolding of the propeptide from the enzymatic cleft (Danser et al 2008) (Figure 3). Initially, the 43-amino acid propeptide moves out of the enzymatic cleft without detaching from the main molecule. Subsequently, the molecule assumes its enzymatically active conformation. Low pH (acid activation) and cold (cryoactivation) are potent stimulants of nonproteolytic activation of prorenin.

When prorenin has been nonproteolytically activated, it is fully active and can be recognized by monoclonal antibodies that are specific for the active site. It is important to note that these antibodies may recognize prorenin even after incubation with a renin inhibitor. This may

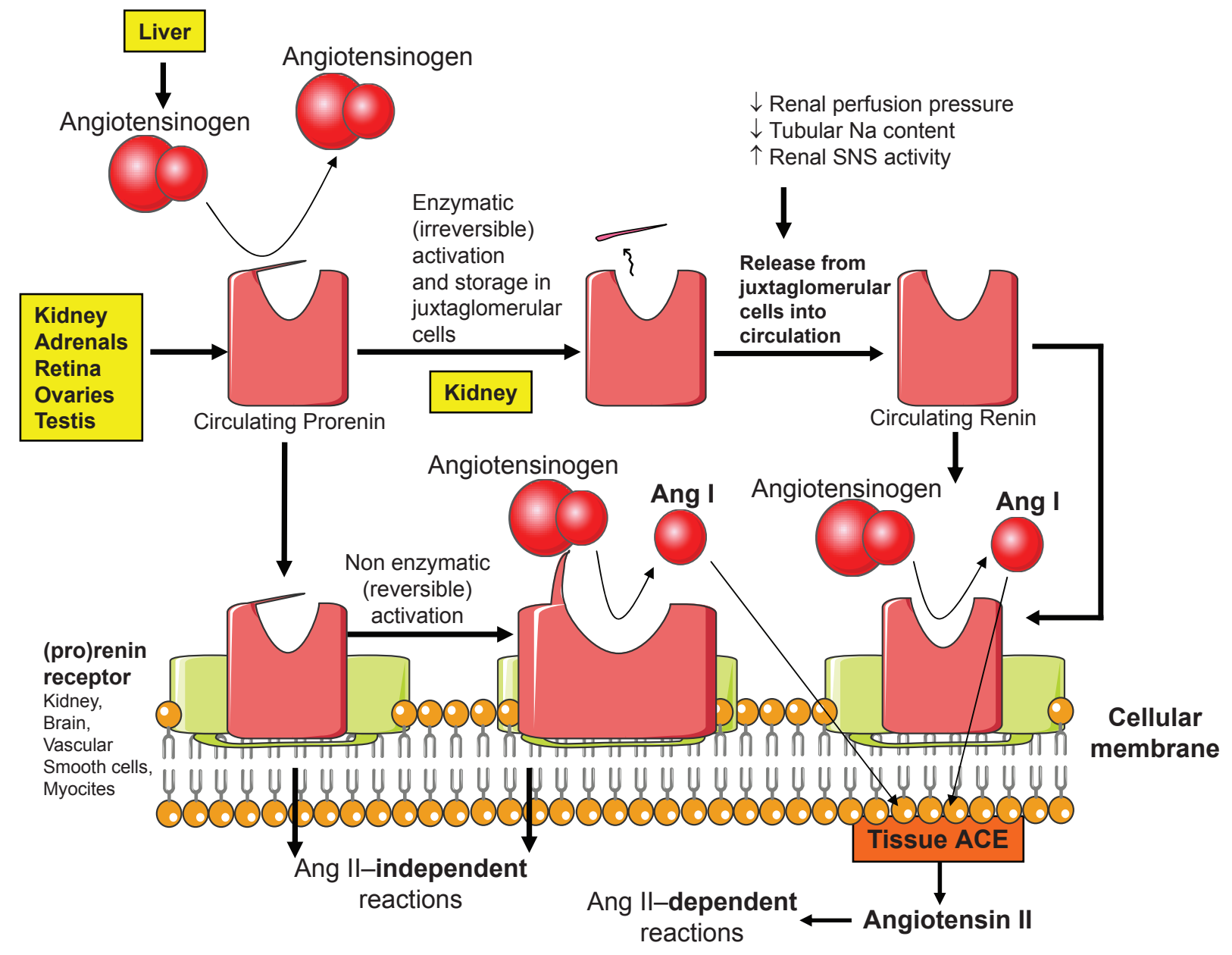

Figure 3 Overview of prorenin, active renin and (pro)renin receptors. 
lead to some overestimation of the degree of reactive prorenin synthesis during direct renin inhibition (Menard et al 2006).

\section{Circulating renin and prorenin}

Circulating levels of renin are $<1 \mathrm{pmol} / \mathrm{L}$ in humans and levels of prorenin are about 10-fold higher (Danser et al 1998). However, circulating levels of prorenin and renin tend to be related. Under physiological conditions, less than $2 \%$ of prorenin is in the active conformation. Acute stimuli may cause a sudden increase in the release of active renin from the juxtaglomerular apparatus without any immediate rise in the prorenin levels, while chronic stimuli may lead to a rise in both renin and prorenin, with a higher rate of conversion of inactive prorenin into active renin (Danser et al 2008). Prorenin has a low intrinsic activity on angiotensinogen which is $<3 \%$ than fully activated renin.
Stimulation of $\mathrm{AT}_{1}$ receptors by Ang II inhibits renin release. In contrast, inhibition of RAS at any level increases renin release by attenuating the negative feedback effect by Ang II (Figure 4).

In patients with diabetes mellitus, as well as during pregnancy, there is usually a rise in prorenin levels with an increased prorenin/renin ratio. In patients with diabetes, prorenin levels may even predict the occurrence of subsequent nephropathy (Luetscher et al 1985; Price et al 1999).

\section{Renin and prorenin receptors}

Most of Ang II generated in the heart and vessels derives from the active renin generated in the kidney and removed from the circulation at tissue level. However, recent data suggest that circulating prorenin may be sequestrated from blood through specific receptors and converted into active renin in tissues. Several receptors for prorenin and

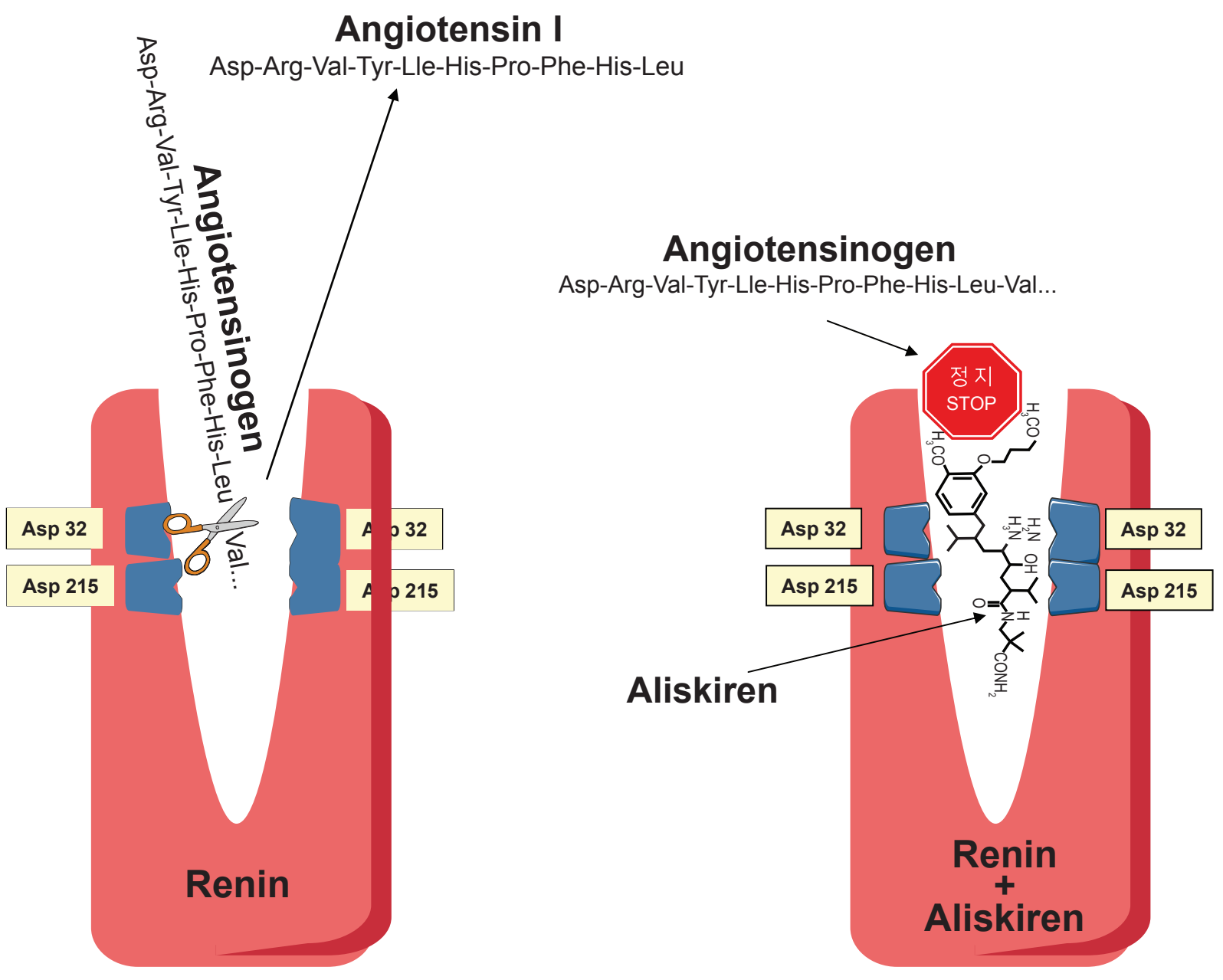

Figure 4 Effect of active renin on angiotensinogen and blockade by aliskiren. 
renin have been described in different tissues including kidney (mesangium and collecting tubules), brain, vascular smooth muscle, and cardiac myocites (Nguyen et al 2002).

Because both renin and prorenin competitively bind to these receptors, the term '(pro)renin' receptors has been introduced. Binding affinity of these receptors is higher for prorenin than for renin (Nabi et al 2006).

When circulating prorenin binds to (pro)renin receptors it undergoes, to effect binding, some conformational changes, without cleaving of the 43-amino acid segment, with enlargement of the cleft and consequent enzymatic activation (Figure 3). This phenomenon of nonproteolytic activation occurs at the surface of the cell (ie, without internalization of prorenin). It could lead to local generation of Ang I from circulating angiotensinogen. Because synthesis of Ang I occurs in close proximity to tissue $\mathrm{ACE}$, this may lead to immediate synthesis of Ang II. When circulating renin binds to these receptors, its enzymatic activity on angiotensinogen increases, with enhanced local generation of Ang I (Bader and Ganten 2008).

After binding to (pro)renin receptors, renin and prorenin are not internalized into the cell. In contrast, renin and prorenin bound to the mannose-6-phosphate receptor (M6P-R), a clearance receptor, may be internalized (van Kesteren et al 1997).

An important question to address is whether the binding capacity of (pro)renin receptors for circulation renin and prorenin is enough for the picomolar concentrations of renin and prorenin that occur in vivo. In fact, experimental studies of (pro)renin receptors often used very high concentrations of renin and prorenin, much in excess of those normally occurring in vivo.

Localization of renin and prorenin in the heart is particularly attractive (Bader and Ganten 2008). Both renin and prorenin bind to (pro)renin receptors located on the membranes of endothelial cells, vascular smooth cells and myocites. In the same time, renin and prorenin diffuse slowly into the interstitial space, reaching interstitial concentrations similar to those in plasma.

Once sequestrated into tissues, circulating renin and prorenin not only enhance local Ang II synthesis, but also directly trigger Ang-II independent reactions which might be potentially active on the development of atherosclerotic plaque (Nguyen 2006; Oliver 2006). These reactions include:

a) Activation of intracellular kinases.

b) Stimulation of DNA synthesis.

c) Increased release of plasminogen activator inhibitor (PAI-1) and transforming growth factor (TGF)- $\beta$ (Ichihara et al 2006; Nguyen and Danser 2006).
It is important to note that these reactions may occur in the absence of Ang II action, as suggested by the inability of ACE inhibitors or angiotensin II receptor blockers to block these effects (Huang et al 2006).

It will be very important to clarify whether specific renin inhibitors can inhibit these Ang-II independent reactions triggered by activated renin at the tissue level and whether such an effect may lead to beneficial effects potentially specific for this class of drugs.

\section{Aliskiren}

Aliskiren, a 2(S),4(S), 5(S), 7(S)-N-(2-carbamoyl2-methylpropyl)-5-amino-4-hydroxy-2,7-diisopropyl-8(4-methoxy-3-[3-methoxypropoxy-]phenyl)-octanamide, is the only orally active renin inhibitor that successfully progressed to phase III trials and extensive clinical use.

\section{Chemical properties}

Aliskiren is a low-molecular-weight hydrophilic nonpeptide which exerts a potent and specific competitive inhibition on renin in primates (Wood et al 2003) (Figure 5). The very high specificity for renin (10,000-fold higher affinity for renin than for other aspartic peptidases) makes aliskiren unlikely to cause adverse effects potentially related to inhibition of other peptidases.

Because renin is a water-soluble protein that can be studied with crystallographic analysis (Rahuel et al 2000), the opportunity arose to examine systematically the crystals of renin bond to renin inhibitors. Consequently, the development of aliskiren was the result of successive steps of molecular modeling on earlier peptide-like renin inhibitors (Wood et al 2003). These steps were aimed to improve the affinity for the active enzymatic subpocket of renin and to prolong the duration of action of the drug.

The high potency of aliskiren is reflected by the finding that the concentration at which this drug can inhibit $50 \%$ of renin activity is only $0.6 \mathrm{nmol} / \mathrm{L}$ (Wood et al 2003).

After oral administration in healthy volunteers, the plasma concentration of aliskiren increases in a dosedependent fashion with peak concentrations after 3-6 hours, average plasma half-life of 23.7 hours (range 20-45 hours), oral bioavailability of about $5 \%$ (for $95 \%$ it is excreted unchanged in feces), and plasma steady-state levels after 5-8 days of treatment (Waldmeier et al 2007).

Of particular note, aliskiren is not subject to metabolism by the cytochrome P450 and does not interact with metabolism of warfarin and a number of other compounds including lovastatin, atorvastatin, digoxin, atenolol, celecoxib, 


\begin{tabular}{|c|c|c|c|}
\hline & $\begin{array}{l}\text { Direct Renin } \\
\text { Inhibitors }\end{array}$ & $\begin{array}{l}\text { ACE } \\
\text { Inhibitors }\end{array}$ & $\begin{array}{l}\text { Angiotensin I Receptor } \\
\text { Blockers }\end{array}$ \\
\hline \multicolumn{4}{|c|}{ Plasma Renin Concentration } \\
\hline \multicolumn{4}{|c|}{ Plasma Renin Activity } \\
\hline \multicolumn{4}{|l|}{ Angiotensin I } \\
\hline \multicolumn{4}{|l|}{ Angiotensin II } \\
\hline \multicolumn{4}{|l|}{ Angiotensin 1-7 } \\
\hline Bradychinin & Unchanged & & Unchanged \\
\hline AT $_{1}$ Receptors & Not stimulated & Not stimulated & Blocked \\
\hline $\mathrm{AT}_{2}$ Receptors & Not stimulated & Not stimulated & Stimulated \\
\hline
\end{tabular}

Figure 5 Similarities and differences between direct renin inhibitors, ACE inhibitors, and angiotensin I receptor blockers.

metformine, ramipril, hydrochlorothiazide, and cimetidine (Dieterle et al 2004, 2005).

\section{Pharmacodynamic properties}

Since important molecular differences exist in the structure of renin and angiotensinogen between different species, inhibitors of human renin are specific for primates and ineffective or scarcely effective in nonprimates. In sodiumdepleted marmosets (which are primates), aliskiren at $3 \mathrm{mg} / \mathrm{kg}$ daily completely inhibited PRA for 24 hours (Wood et al 2005). The effect of aliskiren on blood pressure (BP) was dose-dependent, with a persistence of the effect for 24 hours.

In marmosets, aliskiren was more effective than other renin inhibitors (zanchiren and remikiren) in lowering BP.

In order to obviate the specificity of aliskiren for primate renin, double transgenic rats were developed with human genes for renin and angiotensinogen (Ganten et al 1992; Fukamizu et al 1993). In these rats, low and high doses of aliskiren and valsartan were compared with placebo to investigate their effects on left ventricular hypertrophy, creatinine, albuminuria, and mortality. In summary, both doses of aliskiren but only the higher dose of valsartan decreased all of the above end-points compared with placebo. After 3 weeks, $74 \%$ of rats treated with the low valsartan dose, but $100 \%$ of rats treated with the high valsartan dose and both aliskiren doses survived, compared with none of the the untreated rats (Pilz et al 2005).
A group of healthy normotensive volunteers put on a constant sodium diet $(100 \mathrm{mmol} /$ day $)$ received aliskiren (40-80 mg/day or 160-640 mg/day), enalapril (20 mg/day) or placebo. Aliskiren decreased PRA, Ang I, and Ang II in a dose-dependent fashion. In comparison with placebo, the higher dose of aliskiren reduced Ang II by $80 \%$ and increased plasma renin concentration by more than 10 times. The reduction in Ang II was comparable between enalapril $20 \mathrm{mg} /$ day and aliskiren $160 \mathrm{mg}$ /day. Neither BP nor heart rate were affected by aliskiren and enalapril in these normotensive subjects (Nussberger et al 2002).

In a within-subject study, 12 sodium-depleted normotensive subjects were randomly given placebo, aliskiren $300 \mathrm{mg} /$ day, valsartan $160 \mathrm{mg} /$ day, and the combination of aliskiren and valsartan $(150 \mathrm{mg} /$ day $+80 \mathrm{mg} /$ day $)$. As expected, aliskiren alone decreased PRA while valsartan alone increased PRA, Ang I and Ang II. The combination of aliskiren and valsartan completely eliminated the rise in PRA elicited by valsartan (Azizi et al 2004).

\section{Studies in hypertension}

In placebo-controlled studies in hypertensive subjects (Kushiro et al 2006; Mitchell 2006; Jordan et al 2007; Oh et al 2007; Oparil et al 2007; Pool et al 2007; Villamil et al 2007), aliskiren produced a dose-related BP reduction at doses between 75 and $300 \mathrm{mg} /$ day. There was little or no effect below $75 \mathrm{mg}$, and no additional BP-lowering effect above $300 \mathrm{mg}$. Most of the effect on BP occurred 
after 2 weeks, and a near maximal effect was noted after 4 weeks. A pooled analysis by Dahlof et al (2007) showed mean reductions in systolic BP of 5.9, 12.5, and $15.2 \mathrm{mmHg}$ with placebo, aliskiren $150 \mathrm{mg} /$ day, and aliskiren $300 \mathrm{mg} /$ day. The corresponding mean reductions in diastolic BP were 6.2, 10.1, and $11.8 \mathrm{mmHg}$, respectively. Interestingly, the antihypertensive response to aliskiren was comparable in men and women, and also between subjects of different age.

The long pharmacological half-life of aliskiren makes this drug very suitable for once-daily use. In studies with 24-hour ambulatory BP monitoring (Stanton et al 2003; Gradman et al 2005b), aliskiren effectively reduced BP for 24 hours with a through-to-peak ratio of $98 \%$ for the daily $300 \mathrm{mg} /$ day dose, and $64 \%$ for the $150 \mathrm{mg}$ /day dose.

In a double-blind study (Oparil et al 2007), 1797 hypertensive patients were randomly assigned to receive aliskiren $150 \mathrm{mg} /$ day alone, valsartan $160 \mathrm{mg}$ /day alone, a combination of aliskiren and valsartan, or placebo for 4 weeks. Then the dose in each arm was doubled to the maximum recommended dose (300 and $320 \mathrm{mg} /$ day, respectively) for another 4 weeks. At 8 weeks, the combination of aliskiren and valsartan lowered diastolic BP from baseline by $12.2 \mathrm{~mm}$ $\mathrm{Hg}$, more than monotherapy with aliskiren $(-9.0 \mathrm{mmHg})$, valsartan $(-9.7 \mathrm{mmHg})$, or placebo $(-4.1 \mathrm{mmHg})$. Adverse events and laboratory abnormalities were similar in the four groups. This study suggests that the combination of aliskiren and valsartan at the maximum recommended doses provides greater reductions in BP than monotherapy with either agent, with a tolerability profile not dissimilar from that of monotherapies. To explain these data, it should be considered that the RAS is a self-regulating system which is controlled by a negative feedback inhibition. The stimulation of the $\mathrm{AT}_{1}$ receptors by Ang II immediately suppresses the release of renin from the juxtaglomerular cells. Angiotensin receptor blockade stimulates renin production by inhibiting the action of Ang II on $\mathrm{AT}_{1}$ receptors. Such compensatory activation of the RAS may limit the efficacy of AT receptor $_{1}$ blockers and therefore the simultaneous administration of a direct renin inhibitor such as aliskiren may produce a better antihypertensive response.

Aliskiren has been compared with several antihypertensive drugs including hydrochlorothiazide, ramipril, lisinopril, losartan, irbesartan, and valsartan (Stanton et al 2003; Gradman et al 2005a; Uresin et al 2006; Andersen et al 2007; Oparil et al 2007; Strasser et al 2007; Villamil et al 2007). In general, the antihypertensive effect of aliskiren was similar to that of active comparators. As expected, no rise in PRA occurred with aliskiren, at variance with the active comparators, in the trials which it was assessed.

As a results of these studies, the US Food and Drug Administration approved the use of aliskiren in hypertension up to a maximal dose of $300 \mathrm{mg} /$ day.

\section{Trials on intermediate end-points}

Some important phase-III clinical trials have just been completed. These trials tested the effect of aliskiren on markers of organ damage in approximately 300-500 patients.

a) The Aliskiren in Left-Ventricular Hypertrophy trial (ALLAY, registration number [http://clinicaltrial.gov] NCT00219141) (Solomon 2008) was a randomized between-patient comparison of aliskiren, losartan, and their combination in hypertensive subjects with leftventricular hypertrophy. The primary endpoint consisted in the changes in left-ventricular mass as assessed by magnetic resonance imaging. After 34 weeks of treatment, left ventricular mass decreased slightly more with aliskiren + losartan $(-6.4 \%)$ than it did with aliskiren alone $(-5.4 \%)$ or losartan alone $(-4.7 \%)$, although the differences between the three groups were not statistically significant.

b) The Aliskiren Observation of Heart Failure Treatment trial (ALOFT, NCT00219011) (McMurray et al 2008) was a randomized between-patient comparison of aliskiren $150 \mathrm{mg} /$ day and placebo (on top of standard treatment including ACE inhibitors or angiotensin receptor blockers) in patients with heart failure. The primary endpoint consisted in the changes in the plasma concentration of $\mathrm{N}$-terminal pro brain natriuretic peptide (NT-proBNP). Plasma levels of NT-proBNP rose by about $762 \mathrm{pg} / \mathrm{mL}$ with placebo and fell by $244 \mathrm{pg} / \mathrm{mL}$ with aliskiren $(p=0.0106)$. Aliskiren also reduced BNP and urinary (but not plasma) aldosterone. Thus, the ALOFT study demonstrated that the addition of aliskiren to an optimal therapy (which includes ACE inhibitors, angiotensin receptor blockers, and $\beta$-blockers) in patients with heart failure has favorable neurohumoral effects and is very well tolerated

c) The Aliskiren in the Evaluation of Proteinuria In Diabetes trial (AVOID, NCT00219206) (Parving et al 2008) was a randomized between-patient comparison between aliskiren $(150 \mathrm{mg} /$ day for 3 months and then $300 \mathrm{mg} /$ day for other 3 months and placebo in addition to losartan 100 $\mathrm{mg}$ /day in diabetic patients. Treatment of aliskiren reduced the mean urinary albumin-to-creatinine ratio by $20 \%$ (95\% CI, 9-30; p < 0.001). A reduction by $50 \%$ or more 
was noted in $24.7 \%$ of patients under aliskiren and $12.5 \%$ of patients under placebo $(\mathrm{p}<0.001)$. BP was $2 / 1 \mathrm{mmHg}$ lower with aliskiren than with placebo and tolerability was the same in the two groups. The authors concluded that the renoprotective effects of aliskiren are independent of its antihypertensive effect in patients with hypertension, type 2 diabetes, and nephropathy who are being treated with an angiotensin receptor blocker (ARB).

\section{The future of aliskiren}

Aliskiren is the first orally active direct renin inhibitor to successfully reach the market. Aliskiren blocks the generation of Ang I from angiotensinogen, the initial and rate-limiting step of the RAS, by inhibiting the active enzymatic site of renin. Not dissimilarly from other renin inhibitors, the BP-lowering affect of aliskiren is associated with a decreased, not increased, generation of Ang I. Conversely, plasma renin concentration markedly increases with aliskiren because the drug blocks the negative feedback exerted by Ang II on renin synthesis. Such an increase has been reported to be up to 34-fold (ie, much superior than that induced by ACE inhibitors or angiotensin receptor blockers). It will be important to clarify whether these very high levels of renin may exert biologically unwanted effects through stimulation of (pro)renin receptors.

It will be also important to verify whether the levels of Ang I and Ang II will remain suppressed during chronic therapy, in the absence of biologically relevant ACE-escapelike phenomena. However, while concern about the escape phenomena usually focuses on the return of angiotensin II to pretreatment levels, the decreased PRA may be equally or more important since pre-treatment PRA is an independent risk factor for myocardial infarction in hypertensive patients and for microvascular complications in diabetes (McInnes 2007). Although aliskiren increases plasma renin concentrations, PRA remains suppressed because cleavage of angiotensinogen is blocked.

The inhibition of Ang I generation is the unique feature that differentiates aliskiren not only from traditional antihypertensive drugs which activate the RAS (such as diuretics and calcium channel blockers), but also from ACE inhibitors and angiotensin receptor blockers. In addition, another promising feature of aliskiren is the potential for inhibiting renin and activated prorenin when they are bound to the (pro)renin receptors. On the other hand, aliskiren is unable to block the binding of prorenin and renin to (pro)renin receptors.

Because locally activated renin, as well as prorenin, may trigger reactions that can stimulate atherosclerosis, aliskiren might offer the additional opportunity of inhibiting progression of atherosclerosis at tissue level. Of course, these effects require further experimental and clinical testing.

The antihypertensive effect of aliskiren monotherapy seems to be comparable to that of ACE inhibitors, angiotensin receptor blockers, and other antihypertensive agents at equipotent doses. However, its antihypertensive efficacy is enhanced by drugs that trigger a reactive increase in the PRA such as diuretics, ACE inhibitors and angiotensin receptor blockers (Stanton et al 2003; Gradman et al 2005a; Uresin et al 2006; Andersen et al 2007; Oparil et al 2007; Strasser et al 2007; Villamil et al 2007).

Aliskiren seems to be particularly indicated in patients who are intolerant to ACE inhibitors, as well as in those with elevated RAS activity, white subjects, and young people.

Aliskiren shares with the Ang II receptor blockers a placebo-like tolerability profile (Weir et al 2006). In contrast to ACE inhibitors, aliskiren does not inhibit degradation of bradykinin. This might result in a lesser BP-lowering effect, outweighed by a better tolerability. In addition, the preferential hepatic elimination route of the drug and the lack of interference with several agents including warfarin and statins further enhance the tolerability profile of the drug. The hepatic elimination route makes aliskiren safe in patients with renal failure. Similarly to ACE inhibitors and Ang II receptor blockers, pregnancy and bilateral renal artery stenosis are established contraindications to the use of the drug.

On the basis of the above considerations, hypertension and heart failure are the two conditions in which the effects aliskiren can be exploited most. However, the efficacy of aliskiren in reducing major clinical events requires to be verified in large clinical trials. One of these trials, ALTITUDE (ALiskiren Trial In Type 2 diabetes Using cardio-renal Disease End-point), is ongoing. ALTITUDE is a randomized, placebo-controlled, double-blind study carried out in about 8600 patients with type 2 diabetes associated with persistent macroalbuminuria, persistent microalbuminuria, or a history of cardiovascular disease with reduced renal function. This is an event-driven study that will be concluded when 1628 patients will experience the primary end-point (composite of cardiovascular and renal events). Enrollment began in October 2007 and the study is expected to finish in 2012 .

Two other studies are being planned. The ATMOSPHERE (Aliskiren Trial to Mediate Outcome Prevention in Heart FailuRE) will address heart failure patients similar to those included in ALOFT. Cardiovascular death and re-hospitalization for heart failure will be the components 
of the primary end-point. The APOLLO (Aliskiren in Prevention Of Later Life Outcomes) will address elderly subjects with normal BP $(<140 / 90 \mathrm{mmHg})$, no overt cardiovascular disease, and a high cardiovascular risk profile, in order to test the efficacy of the drug in reducing the risk of major cardiovascular end-points.

Furthermore, because aliskiren inhibits the initial and rate-limiting step of the RAS, it might become a reasonable therapeutic choice also in a broad number of clinical conditions, sharing an increased cardiovascular risk, where the inhibition of the RAS has been shown to be beneficial. These conditions include stable coronary artery disease, cerebrovascular disease, diabetes, and peripheral arterial disease. A recent trial suggests that the ARB telmisartan is as good as ('non inferior' to) ramipril in these patients, although the tolerability profile of telmisartan was superior to that of ramipril and the combination of the two drugs was not superior to the single ones (The 2008). Aliskiren has the potential to be useful in this wide spectrum of conditions. This would require the demonstration of non-inferiority versus other drugs inhibiting the RAS (ACE inhibitors, angiotensin receptor blockers) in properly designed clinical trials.

\section{Acknowledgments}

The authors wish to thank the Fondazione Umbria Cuore e Ipertensione - ONLUS, Perugia, Italy for financial support.

\section{Disclosures}

None of the authors has any disclosures to report.

\section{References}

Alderman MH, Madhavan S, Ooi WL, et al. 1991. Association of the reninsodium profile with the risk of myocardial infarction in patients with hypertension. N Engl J Med, 324:1098-104.

Alderman MH, Ooi WL, Cohen H, et al. 1997. Plasma renin activity: a risk factor for myocardial infarction in hypertensive patients. $\mathrm{Am} J$ Hypertens, 10:1-8.

Andersen K, Weinberger MH, Egan B, et al. 2007. Aliskiren-based therapy lowers blood pressure more effectively than ramipril-based therapy in patients with hypertension: a 6-month, randomized, double-blind trial $J$ Am Coll Cardiol, 49(Suppl A):A371.

Azizi M, Menard J, Bissery A, et al. 2004. Pharmacologic demonstration of the synergistic effects of a combination of the renin inhibitor aliskiren and the AT1 receptor antagonist valsartan on the angiotensin II-renin feedback interruption. $J$ Am Soc Nephrol, 15:3126-33.

Bader M, Ganten D. 2008. Update on tissue renin-angiotensin systems. J Mol Med 86:615-21.

Brunner HR, Laragh JH, Baer L, et al. 1972. Essential hypertension: renin and aldosterone, heart attack and stroke. $N$ Engl J Med, 286:441-9.

Campbell DJ, Woodward M, Chalmers JP, et al. 2005. Prediction of myocardial infarction by N-terminal-pro-B-type natriuretic peptide, $\mathrm{C}$-reactive protein, and renin in subjects with cerebrovascular disease. Circulation, 112:110-6.
Clausmeyer S, Sturzebecher R, Peters J. 1999. An alternative transcript of the rat renin gene can result in a truncated prorenin that is transported into adrenal mitochondria. Circ Res, 84:337-44.

Dahlof B, Anderson DR, Arora V, et al. 2007. Aliskiren, a direct renin inhibitor, provides antihypertensive efficacy and excellent tolerability independent of age or gender in patients with hypertension. $J$ Clin Hypertens, 9(Suppl A):A157.

Danser AH, Batenburg WW, van Esch JH, et al. 2008. Prorenin anno 2008. $J$ Mol Med, 86:655-8.

Danser AH, Derkx FH, Schalekamp MA, et al. 1998. Determinants of interindividual variation of renin and prorenin concentrations: evidence for a sexual dimorphism of (pro)renin levels in humans. J Hypertens, $16: 853-62$.

Danser AH, van den Dorpel MA, Deinum J, et al. 1989. Renin, prorenin, and immunoreactive renin in vitreous fluid from eyes with and without diabetic retinopathy. J Clin Endocrinol Metab, 68:160-7.

Derkx FH, Alberda AT, de Jong FH, et al. 1987. Source of plasma prorenin in early and late pregnancy: observations in a patient with primary ovarian failure. J Clin Endocrinol Metab, 65:349-54.

Derkx FH, Schalekamp MA. 1988. Human prorenin: pathophysiology and clinical implications. Clin Exp Hypertens A, 10:1213-25.

Dieterle W, Corynen S, Mann J. 2004. Effect of the oral renin inhibitor aliskiren on the pharmacokinetics and pharmacodynamics of a single dose of warfarin in healthy subjects. Br J Clin Pharmacol, 58:433-6.

Dieterle W, Corynen S, Vaidyanathan S, et al. 2005. Pharmacokinetic interactions of the oral renin inhibitor aliskiren with lovastatin, atenolol, celecoxib and cimetidine. Int J Clin Pharmacol Ther, 43:527-35.

Donoghue M, Hsieh F, Baronas E, et al. 2000. A novel angiotensinconverting enzyme-related carboxypeptidase (ACE2) converts angiotensin I to angiotensin 1-9. Circ Res, 87:E1-9.

Doyle AE, Jerums G, Johnston CI, et al. 1973. Plasma renin levels and vascular complications in hypertension. Br Med J, 2(5860):206-7.

Fukamizu A, Sugimura K, Takimoto E, et al. 1993. Chimeric reninangiotensin system demonstrates sustained increase in blood pressure of transgenic mice carrying both human renin and human angiotensinogen genes. J Biol Chem, 268:11617-21.

Ganten D, Wagner J, Zeh K et al. 1992. Species specificity of renin kinetics in transgenic rats harboring the human renin and angiotensinogen genes. Proc Natl Acad Sci U S A, 89:7806-10.

Gradman AH, Schmieder RE, Lins RL, et al. 2005a. Aliskiren, a novel orally effective renin inhibitor, provides dose-dependent antihypertensive efficacy and placebo-like tolerability in hypertensive patients. Circulation, 111:1012-8.

Gradman AH, Schmieder RE, Lins RL, et al. 2005b. Aliskiren, a novel orally effective renin inhibitor, provides dose-dependent antihypertensive efficacy and placebo-like tolerability in hypertensive patients. Circulation, 111:1012-8

Huang Y, Wongamorntham S, Kasting J, et al. 2006. Renin increases mesangial cell transforming growth factor-beta1 and matrix proteins through receptor-mediated, angiotensin II-independent mechanisms. Kidney Int, 69:105-13.

Ichihara A, Suzuki F, Nakagawa T, et al. 2006. Prorenin receptor blockade inhibits development of glomerulosclerosis in diabetic angiotensin II type 1a receptor-deficient mice. J Am Soc Nephrol, 17:1950-61.

Itskovitz J, Rubattu S, Levron J, et al. 1992. Highest concentrations of prorenin and human chorionic gonadotropin in gestational sacs during early human pregnancy. J Clin Endocrinol Metab, 75:906-10.

Itskovitz J, Sealey JE, Glorioso, et al. 1987. Plasma prorenin response to human chorionic gonadotropin in ovarian-hyperstimulated women: correlation with the number of ovarian follicles and steroid hormone concentrations. Proc Natl Acad Sci U S A, 84:7285-9.

Jacoby DS, Rader DJ. 2003. Renin-angiotensin system and atherothrombotic disease: from genes to treatment. Arch Intern Med, 163:1155-64.

James MN, Sielecki AR. 1985. Stereochemical analysis of peptide bond hydrolysis catalyzed by the aspartic proteinase penicillopepsin. Biochemistry, 24:3701-13. 
Jordan J, Engeli S, Boye SW, et al. 2007. Direct renin inhibition with aliskiren in obese patients with arterial hypertension. Hypertension, 49:1047-55.

Kushiro T, Itakura H, Abo Y, et al. 2006. Aliskiren, a novel oral renin inhibitor, provides dose-dependent efficacy and placebo-like tolerability in Japanese patients with hypertension. Hypertens Res, 29:997-1005.

Luetscher JA, Kraemer FB, Wilson DM, et al. 1985. Increased plasma inactive renin in diabetes mellitus. A marker of microvascular complications. N Engl J Med, 312:1412-7.

McInnes GT. 2007. Renin inhibition: the holy grail of renin-angiotensin system blockade? J Hum Hypertens, 21:766-9.

McMurray JJV, Pitt B, Latini R, et al; for the Aliskiren Observation of Heart Failure Treatment, I. 2008. Effects of the oral direct renin inhibitor aliskiren in patients with symptomatic heart failure. Circ Heart Fail, 1:17-24.

Meade TW, Cooper JA, Peart WS. 1993. Plasma renin activity and ischemic heart disease. $N$ Engl J Med, 329:616-9.

Menard J, Guyene TT, Peyrard S, et al. 2006. Conformational changes in prorenin during renin inhibition in vitro and in vivo. J Hypertens, 24:529-34.

Mitchell J, Oh B, Herron J, et al. 2006. Once-daily aliskiren provides effective, smooth 24-h blood pressure control in patients with hypertension. J Clin Hypertens, 8(Suppl A):A93.

Nabi AH, Kageshima A, Uddin MN, et al. 2006. Binding properties of rat prorenin and renin to the recombinant rat renin/prorenin receptor prepared by a baculovirus expression system. Int $J \mathrm{Mol} \mathrm{Med,} \mathrm{18:483-8}$.

Nguyen G. 2006. Renin/prorenin receptors. Kidney Int, 69:1503-6.

Nguyen G, Danser AH. 2006. The (pro)renin receptor: therapeutic consequences. Expert Opin Investig Drugs, 15:1131-5.

Nguyen G, Delarue F, Burckle C, et al. 2002. Pivotal role of the renin/ prorenin receptor in angiotensin II production and cellular responses to renin. J Clin Invest, 109:1417-27.

Nussberger J, Wuerzner G, Jensen C, et al. 2002. Angiotensin II suppression in humans by the orally active renin inhibitor Aliskiren (SPP100): comparison with enalapril. Hypertension, 39:E1-8.

Oh BH, Mitchell J, Herron JR, et al. 2007. Aliskiren, an oral renin inhibitor, provides dose-dependent efficacy and sustained 24-hour blood pressure control in patients with hypertension. $J$ Am Coll Cardiol, 49:1157-63.

Oliver JA. 2006. Receptor-mediated actions of renin and prorenin. Kidney Int, 69:13-5.

Oparil S, Yarows SA, Patel S, et al. 2007. Efficacy and safety of combined use of aliskiren and valsartan in patients with hypertension: a randomised, double-blind trial. Lancet, 370(9583):221-9.

Parving HH, Persson F, Lewis JB, et al. 2008. Aliskiren combined with losartan in type 2 diabetes and nephropathy. $N$ Engl $J$ Med, 358:2433-46.

Pilz B, Shagdarsuren E, Wellner M, et al. 2005. Aliskiren, a human renin inhibitor, ameliorates cardiac and renal damage in double-transgenic rats. Hypertension, 46:569-76.

Pool JL, Schmieder RE, Azizi M, et al. 2007. Aliskiren, an orally effective renin inhibitor, provides antihypertensive efficacy alone and in combination with valsartan. Am J Hypertens, 20:11-20.

Price DA, Porter LE, Gordon M, et al. 1999. The paradox of the low-renin state in diabetic nephropathy. J Am Soc Nephrol, 10:2382-91.

Rahuel J, Rasetti V, Maibaum J, et al. 2000. Structure-based drug design: the discovery of novel nonpeptide orally active inhibitors of human renin. Chem Biol, 7:493-504.
Reudelhuber TL, Ramla D, Chiu L, et al. 1994. Proteolytic processing of human prorenin in renal and non-renal tissues. Kidney Int, 46:1522-4.

Schmidt-Ott KM, Kagiyama S, et al. 2000. The multiple actions of angiotensin II in atherosclerosis. Regul Pept, 93:65-77.

Sealey JE, Goldstein M, Pitarresi T, et al. 1988. Prorenin secretion from human testis: no evidence for secretion of active renin or angiotensinogen. J Clin Endocrinol Metab, 66:974-8.

Sielecki AR, Hayakawa K, Fujinaga M, et al. 1989. Structure of recombinant human renin, a target for cardiovascular-active drugs, at 2.5 A resolution. Science, 243(4896):1346-51.

Skeggs LT Jr, Kahn JR, Lentz K, et al. 1957. The preparation, purification, and amino acid sequence of a polypeptide renin substrate. $J$ Exp Med, 106:439-53.

Solomon SD. 2008. Effect of the direct renin inhibitor aliskiren, either alone or in combination with losartan, compared to losartan, on left ventricular mass in patients with hypertension and left ventricular hypertrophy: The Aliskiren Left Ventricular Assessment of Hypertrophy (ALLAY) Trial. SCAI-ACC i2 Summit/American College of Cardiology Annual Scientific Session, Chicago, IL.

Stanton A, Jensen C, Nussberger J, et al. 2003. Blood pressure lowering in essential hypertension with an oral renin inhibitor, aliskiren. Hypertension, 42:1137-43.

Strasser RH, Puig JG, Farsang C, et al. 2007. A comparison of the tolerability of the direct renin inhibitor aliskiren and lisinopril in patients with severe hypertension. J Hum Hypertens, 21780-7.

The OI. 2008. Telmisartan, ramipril, or both in patients at high risk for vascular events. $N$ Engl J Med, 358:1547-59.

Turner AJ. 2003. Exploring the structure and function of zinc metallopeptidases: old enzymes and new discoveries. Biochem Soc Trans, 31:723-7.

Uresin Y, Taylor A, Kilo C, et al. 2006. Aliskiren, a novel renin inhibitor, has greater BP lowering than ramipril and additional BP lowering when combined with ramipril in patients with diabetes and hypertension. J Hypertens, 24(Suppl 4):82.

van Kesteren CA, Danser AH, Derkx FH, et al. 1997. Mannose 6-phosphate receptor-mediated internalization and activation of prorenin by cardiac cells. Hypertension, 30:1389-96.

Villamil A, Chrysant SG, Calhoun D, et al. 2007. Renin inhibition with aliskiren provides additive antihypertensive efficacy when used in combination with hydrochlorothiazide. J Hypertens, 25:17-26.

Waldmeier F, Glaenzel U, Wirz B, et al. 2007. Absorption, distribution, metabolism, and elimination of the direct renin inhibitor aliskiren in healthy volunteers. Drug Metab Dispos, 35:418-28.

Weir M, Bush C, Zhang J, et al. 2006. Antihypertensive efficacy and safety of the oral renin inhibitor aliskiren in patients with hypertension: a pooled analysis. Eur Heart J, 27(Suppl):299.

Wilkinson-Berka JL. 2004. Diabetes and retinal vascular disorders: role of the renin-angiotensin system. Expert Rev Mol Med, 6:1-18.

Wood JM, Maibaum J, Rahuel J, et al. 2003. Structure-based design of aliskiren, a novel orally effective renin inhibitor. Biochem Biophys Res Commun, 308:698-705.

Wood JM, Schnell CR, Cumin F, et al. 2005. Aliskiren, a novel, orally effective renin inhibitor, lowers blood pressure in marmosets and spontaneously hypertensive rats. $J$ Hypertens, 23:417-26.

Wood JM, Stanton JL, Hofbauer KG. 1987. Inhibitors of renin as potential therapeutic agents. $J$ Enzyme Inhib, 1:169-85. 
